Asian Pacific Journal of Reproduction

Journal homepage: www.apjr.net

doi: $10.12980 /$ apjr.6.20170406

@2017 by the Asian Pacific Journal of Reproduction. All rights reserved.

\title{
Effect of melatonin and/or cysteamine on development and vitrification of buffalo embryos
}

\author{
Mohamed MM El-Sokary ${ }^{1}$, Mohamed El-Raey ${ }^{1 凶}$, Karima GhM Mahmoud ${ }^{2}$, Mahmoud EA Abou El-Roos ${ }^{1}$, \\ Gamal MS Sosa ${ }^{1}$ \\ ${ }^{I}$ Department of Theriogenology, Faculty of Veterinary Medicine, Benha University, P.O: 13736, Tokh, Kaliobia, Egypt \\ ${ }^{2}$ Department of Anim. Reprod. \& A. I., National Research Center, Dokki, Giza, Egypt
}

\section{ARTICLE INFO}

Article history:

Received 10 March 2017

Revision 16 April 2017

Accepted 20 April 2017

Available online 1 July 2017

Keywords:

Melatonin

Cysteamine

Buffalo

Oocyte

Maturation

Vitrification
ABSTRACT

Objective: To assess the effects of melatonin and/or cysteamineon in vitro maturation, culturing and post-warming of buffalo embryos. Methods: Buffalo oocytes were classified into control, cysteamine $(50 \mu \mathrm{M})$, melatonin $(10 \mathrm{ng} / \mathrm{mL})$ and cysteamine $(50 \mu \mathrm{M})+$ melatonin $(10 \mathrm{ng} / \mathrm{mL})$ treatment groups. In experiment 1 , previous treatments were added during in vitro maturation and culturing of buffalo oocytes. Results: Cleavage and blastocyst rates were significantly $(P<0.05)$ increased in melatonin treated group $(70.5 \pm 0.9$ and $12.8 \pm 1.0$, respectively). However this effect was potentiated when combined with cysteamine $(74.0 \pm 1.7$ and 14.8 \pm 1.7 , respectively). In experiment 2 , the treatements were added in maturtaion, culturing as well as post-warming culture media. Embryos at $7 \mathrm{~d}$ were vitrified.Viability assessement directly after warming showed significant increase $(P<0.05)$ in cysteamine, melatonin and their combination groups $(76.8 \pm 2.8,80.0 \pm 2.1$ and $83.3 \pm 1.7$, respectively) than control $(65.8 \pm 2.4)$; but the viability after $24 \mathrm{~h}$ post-warming was the best in cysteamine + melatonin combination group (61.4 \pm 2.1$)$. Conculsions: Enriching maturation, culturing and post-warming media of buffalo oocytes and embryos with melatonin and/or cysteamine have significantly beneficial effects on oocyte developmental competence as well as embryos vitrification procedure outcomes which in turn resulting in enhancement of commercial buffalo embryo production.

\section{Introduction}

The embryo implantation potential might be dropped to $40 \%$ due to side effects of cryopreservation[1]; this drop was mainly due to reduction in the cryopreserved embryos viability; which lagged behind that of in vivo derived embryos[2,3]. The reasons of this variation were partially understood. Recently, new researches prove that in vitro culture conditions affect oxidative homeostasis by increasing ROS exposure or lessening antioxidant protection resulting in poor quality of embryo developmental competence[4,5]. Furthermore, certain opinions reflected it to the cryopreservation

\footnotetext{
Corresponding author: Mohamed El-Raey, Ph.D.,Department of Theriogenology, Faculty of Veterinary Medicine, Benha University, P.O: 13736, Tokh, Kaliobia, Egypt. Tel: (+2)01003828279 E-mail: elraay_310@yahoo.com
}

process which promotedreactive oxygen species (ROS) production and accumulation[6,7]. Vitrification is rapidefficient technique for embryos cryopreserving[8]. However, successful vitrification involves certain critical points such as: freezing temperature, vitrification medium volumes[9,10], presence or absence of the antioxidants and cryoprotectants that are important detrimental factors during vitrification process[11]. It had been stated that variation in all preceding factors subjected the cryopreserved embryos to become more amenable to the deleterious effects of $\operatorname{ROS}[12,13]$. So, it is important to protect live cells from oxidative

This is an open access article distributed under the terms of the Creative Commons Attribution-Non Commercial-Share Alike 3.0 License, which allows others to remix, tweak and buid upon the work non-commercially, as long as the author is credited and the new creations are licensed under the identical terms.

For reprints contact: reprints@medknow.com

(C)2017 Asian Pacific Journal of Reproduction Produced by Wolters Kluwer- Medknow

How to cite this article: Mohamed MM El-Sokary, Mohamed El-Raey, Karima GhM Mahmoud, Mahmoud EA Abou El-Roos, Gamal MS Sosa. Effect of melatonin and/or cysteamine on development and vitrification of buffalo embryos. Asian Pac J Reprod 2017; 6(4): 176-180. 
stressors during culturing processes. A new approach is to supply the culture medium with antioxidant compounds. In between, Melatonin as indole participates in regulating mammal's biological clock[14]. This indole amine is multifunctional and universal hydrophilic and hydrophobic antioxidant[15]. Furthermore, melatonin metabolites also participate in the interactions with ROS; this phenomenon was referred as a scavenging cascade reaction[2]. Melatonin also stimulates the activity of some antioxidant enzymes including glutathione peroxidase and superoxide dismutase[16,17]. This in turn, resulted in reduction in blastocysts apoptosis and the average apoptotic cell numbers/blastocyst in vitrified two-cell embryos[18]. Furthermore, melatonin prevents protein, DNA damage and lipid peroxidation as it has multiple antioxidant capacities[19]. Additionally, melatonin preserves optimal mitochondrial homeostasis and function by reducing and preventing mitochondrial ROS[20], thereby preventing cell death by limiting apoptotic events[21]. Moreover, melatonin was stated to enhance ROS detoxification during post warming process, where embryos require high metabolic activity to complete the resumption of DNA and protein synthesis[22]. This action may be chiefly effective for cryopreserved in vitro produced embryos, considering their poor cryotolerance[23]. Another example of the perfect antioxidants that could be used efficiently in maturation and culture media is cysteamine. Cysteamine is a thiol compound commonly added to IVM medium to improve the oocyte developmental competence through glutathione (GSH) synthesis[24]. GSH play important antioxidant roles besides it had important effects on amino acid transport, DNA and protein synthesis and disulphides reduction[25,26], by acting on delicate cytoplasmic maturation process[27,28]. Consequently, improved fertilization rate, developmental competence and cryoresistance following vitrification process[29]. Generally, vitrified oocytes were significantly of lower glutathione contents and of high ROS levels[30]; Furthermore, buffalo oocytes characterized by high lipid contents, those two factors exposed the oocyte or embryos to become more sensitive to oxidative damage[27]. Considering these beneficial effects of cysteamine and melatonin on oocyte maturation and embryonic development, there is still little work regarding their effects on embryo vitrification. So this study aimed to assess the effect of melatonin and/or cysteamine during in vitro maturation, development and post-warming process of buffalo embryos.

\section{Material and methods}

\subsection{Cumulus-oocyte complexes (COCs) collection, selection and in vitro maturation}

Buffalo ovaries were collected from the slaughter house in sterile modified Dulbecco's phosphate saline (D-PBS; pH 7.2) containing
$100 \mu \mathrm{g} / \mathrm{mL}$ streptomycin and $100 \mathrm{IU} / \mathrm{mL}$ penicillin at $37^{\circ} \mathrm{C}$. They were washed in D-PBS then in normal saline. Oocytes were aspirated from follicles ranging between 3 and $7 \mathrm{~mm}$ in diameter using 18-gauge needle attached to a disposable 10-ml syringe within 3-5 $\mathrm{h}$ after the animals were slaughtered. Evenly granulated oocytes surrounded with at least two layers of compact cumulus cells and with homogenous cytoplasm were selected for the experiments. Selected COCs were first washed in sterile D-PBS, and then in IVM medium; IVM was performed in TCM-199 (Gibco) supplemented with $10 \%$ calf serum (Gibco) and $50 \mu \mathrm{g} / \mathrm{mL}$ gentamycin (G-1272 Sigma). The COCs were cultured in groups of $10-20 / 100 \mu \mathrm{L}$ drop of IVM medium in Petri-dishes (Nunclone, Roskilde, Denmark) with mineral oil (M-4810, Sigma) overlay for $22 \mathrm{~h}$ at $38.5{ }^{\circ} \mathrm{C}, 5 \%$ $\mathrm{CO}_{2}$ and $95 \%$ humidity. Melatonin $(10 \mathrm{ng} / \mathrm{mL})$ and cystamine (50 $\mu \mathrm{M})$ solutions were prepared in TCM-199, filtered using 0.22-mm filters from Millipore Corporation (Millex GV Co., Cork, Ireland). Melatonin solution was kept at $4{ }^{\circ} \mathrm{C}$ until use for a maximum of 12 d. In IVM and IVC experiments, melatonin was added after testing the ideal concentration for buffalo oocyte maturation and embryo development that differ than cow[31,32].

\subsection{In vitro fertilization (IVF) and culture}

Spermatozoa were treated according to Niwa K and Ohgoda O[33]. Frozen straws were thawed at $35-37{ }^{\circ} \mathrm{C}$ for $1 \mathrm{~min}$ in a water bath. The spermatozoa were washed by centrifugation at $800 \mathrm{~g}$ for 10 min in BO medium[34] containing $10 \mu \mathrm{g} / \mathrm{mL}$ heparin and $2.5 \mathrm{mM}$ caffeine without BSA (Sigma, St. Louis, MO). The sperm pellets were diluted with BO including $20 \mathrm{mg} / \mathrm{mL}$ bovine serum albumin to adjust the concentration of spermatozoa to $12.5 \times 10^{6}$ sperm. Oocytes were washed before introducing to the sperm in $\mathrm{BO}$ medium with $10 \mathrm{mg} / \mathrm{mL}$ BSA, then added into $100 \mu \mathrm{L}$ droplets of diluted sperm (about 5-10 oocytes/droplet). The oocytes and spermatozoa were co-cultured at $5 \% \mathrm{CO}_{2}, 38.5{ }^{\circ} \mathrm{C}, 95 \%$ humidity for $5 \mathrm{~h}$. After that, the oocytes were washed several times in TCM-199 to remove the attached spermatozoa. Groups of 10-20 oocytes were again replaced with previously prepared co-culture $100 \mu \mathrm{L}$ droplet consisting TCM-199, 10\% serum and $50 \mu \mathrm{g} / \mathrm{mL}$ gentamycin and the chosen concentration of melatonin and cystamine. Cleavage was assessed after $72 \mathrm{~h}$ of culture (day $0=$ day of insemination) and the embryos was recorded at the day $7[35]$.

\subsection{Embryo vitrification and warming}

The vitrification solutions were prepared in TCM $199+20 \%$ fetal calf serum. Embryos were vitrified in 1.75 M EG + 1.75 M DMSO for $2.5 \mathrm{~min}$ (step one). Then, in 3.5 MEG + 3.5 M DMSO for $45 \mathrm{~s}$ (second step) in $0.25 \mathrm{~mL}$ straws. Immediately, straws were cooled in liquid nitrogen vapor for $1 \mathrm{~min}$ before storing in liquid nitrogen for 
$1 \mathrm{wk}$. For warming, straws were held in air for $10 \mathrm{~s}$, placed in water at $37{ }^{\circ} \mathrm{C}$ for $30 \mathrm{~s}$, and flicked four to six times to mix columns. Then, embryos were washed in $0.5 \mathrm{M}$ galactose for $5 \mathrm{~min}$ at room temperature. Finally, the embryos were washed five times in TCM plus $5 \% \mathrm{FCS}$ and cultured at $38.5{ }^{\circ} \mathrm{C}, 5 \% \mathrm{CO}_{2}$ for further $24 \mathrm{~h}[36]$.

\subsection{Survival assay}

Embryos were examined morphologically after warming and the viability was evaluated by culturing for $24 \mathrm{~h}$. The embryos developed to advanced stages, were considered to be survived. The morulae that developed into more advanced stage (blastocysts) and the blastocysts that re-expanded were considered as surviving[36].

\subsection{Experimental design}

Experiment 1: Effect of melatonin and/or cysteamine supplementation to IVM and IVC media on oocyte and embryo development. Oocytes were classified into four groups; control, $50 \mu \mathrm{M}$ cysteamine, $10 \mathrm{ng} /$ $\mathrm{mL}$ melatonin and $50 \mu \mathrm{M}$ cysteamine $+10 \mathrm{ng} / \mathrm{mL}$ melatonin. The cysteamine and melatonin were added during the maturation and development of oocytes.

Experiment 2: Effect of melatonin and/or cysteamineon viability of vitrified embryos. All good embryos at day 7 were vitrified using mixtures of DMSO and EG in TCM-199 with two concentrations of cryoprotectants (3.5 and 7.0 M). The four groups of oocytes were matured and cultured as in the first experiment, and then the cysteamine and melatonin were added also at the post-warming culture media.

\subsection{Statistical analysis}

Three replicates per group were statistically analyzed by ANOVA using SPSS version 16.0 statistical software. A comparison of means was carried out by Duncan's Multiple Range test. Differences were considered to be significant at $P<0.05$ level.

\section{Results}

\subsection{Effect of melatonin and/orcysteaminesupplementation to culture media on embryo development}

Table 1 showed that the cleavage rates were significantly increase in melatonin $(P<0.01)$ and cysteamine + melatonin $(P<0.001)$ than control group. Moreover, there were significantly increase in blastocyst rates for melatonin $(P<0.01)$ and cysteamine + melatonin
$(P<0.001)$ compared to control group. There were no significant differences in percentage of cleavage and blastocyst between melatonin and cysteamine + melatonin groups

Table 1

Effect of melatonin and/or cysteamine on buffalo embryo development (nean $\pm \mathrm{SE})$.

\begin{tabular}{llcl}
\hline Treatment & $\begin{array}{c}\text { No. of inseminated } \\
\text { oocytes }\end{array}$ & $\begin{array}{c}\text { Cleavage No } \\
(\%)\end{array}$ & $\begin{array}{c}\text { Blastocysts } \\
\text { No* }(\%)\end{array}$ \\
\hline Control & 210 & $126\left(60.2 \pm 2.4^{\mathrm{c}}\right)$ & $16\left(7.4 \pm 1.2^{\mathrm{c}}\right)$ \\
Cysteamine & 204 & $134\left(66.1 \pm 1.9^{\mathrm{bc}}\right)$ & $18\left(9.1 \pm 1.2^{\mathrm{bc}}\right)$ \\
Melatonin & 232 & $164\left(70.5 \pm 0.9^{\mathrm{ab}}\right)$ & $30\left(12.8 \pm 1.0^{\mathrm{ab}}\right)$ \\
Cysteamine + & 176 & $130\left(74.0 \pm 1.7^{\mathrm{a}}\right)$ & $26\left(14.8 \pm 1.7^{\mathrm{a}}\right)$ \\
Melatonin & & & \\
\hline
\end{tabular}

Values with different superscripts within the same column differ significantly $(P<0.01)$. No. $=$ number

\subsection{Effect of melatonin and/orcysteamine on viability of vitrified embryos.}

The viability of vitrified buffalo embryos directly after warming was significantly increase in cysteamine $(P<0.01)$, melatonin $(P<$ $0.01)$ and cysteamine + melatonin $(P<0.001)$ than control group. But there were no significant differences among the cysteamine, melatonin and cysteamine + melatonin groups in viability directly after warming (Table 2). Furthermore, there was significant increase in viability of embryos after $24 \mathrm{~h}$ post warming in cysteamine + melatonin $(P<0.001)$ than other groups including the control. But, there were no significant differences among control, melatonin and cysteamine groups in viability $24 \mathrm{~h}$ post warming.

Table 2

Effect of melatonin and/or cysteamine on viability of vitrified buffalo embryo (mean \pm SE)

\begin{tabular}{|c|c|c|c|}
\hline Treatment & $\begin{array}{l}\text { No. of vitrified- } \\
\text { warmed embryos }\end{array}$ & $\begin{array}{l}\text { Morphologically } \\
\text { normal embryos } \\
\text { directly after } \\
\text { warming } \\
\text { No }(\%)\end{array}$ & $\begin{array}{l}\text { Post-warming } \\
\text { development after } \\
24 \text { h (viability) } \\
\text { No (\%) }\end{array}$ \\
\hline Control & 86 & $56\left(65.8 \pm 2.4^{\mathrm{b}}\right)$ & $39\left(47.3 \pm 2.6^{b}\right)$ \\
\hline Cysteamine & 69 & $52\left(76.8 \pm 2.8^{\mathrm{a}}\right)$ & $29\left(52.9 \pm 1.6^{\mathrm{b}}\right)$ \\
\hline Melatonin & 270 & $57\left(80.0 \pm 2.1^{\mathrm{a}}\right)$ & $38\left(53.4 \pm 0.7^{\mathrm{b}}\right)$ \\
\hline $\begin{array}{l}\text { Cysteamine + } \\
\text { Melatonin }\end{array}$ & 76 & $63\left(83.3 \pm 1.7^{\mathrm{a}}\right)$ & $47\left(61.4 \pm 2.1^{\mathrm{a}}\right)$ \\
\hline
\end{tabular}

Values with different superscripts within the same column differ significantly $(P<0.01)$. No. $=$ number.

\section{Discussion}

In the current work, the rates of cleavage and blastocyst were significantly increased $(P<0.01)$ when melatonin was added to the maturation and culture media of buffalo oocytes. These results came in agreement with El-Raey et al., El-Raey et al., Manjunatha et al., Cebrian-Serrano et al.[31,32,37,38] who reported beneficial 
effects of melatonin when supplemented to in vitro maturation and culturing media of buffalo and cowembryos. These results were attributed to the efficient anti-oxidative activity of melatonin. Where, melatonin was found to directly interact with ROS and stimulates the activity of some antioxidant enzymes as superoxide dismutase, glutathione peroxidase, and catalase[16,17]. Also, melatonin prevents lipid peroxidation[39]; protein, and DNA[19,40]. In addition, it was found that melatonin preserve the function of mitochondria through reducing and preventing ROS[20], as well as enhancing mitochondrial distribution activity and patterns during nuclear maturation phase[31], and preventing or reducing apoptosis level[21]. Lately, it had been stated that melatonin can ensure its valuable effects through activation of MTNR1A receptorin both granulosa cells and oocyte[31,32], and MTNR1B receptor only in cumulus cells[31,32,41]. In the present study, viability of buffalo embryos directly after thawing was significantly increased $(P<0.05)$ in cysteamine, melatonin and cysteamine+melatonin groups than control. But in cysteamine+melatonin combination group, the viability at $24 \mathrm{~h}$ post thawing was the best. It was reported that presence or absence of the antioxidant are important determinable factors during vitrification process[11,30].

Melatonin beneficial effects on buffalo embryo development during post-warming culture were mainly due to oxidative index reduction[23]. It had been reported that ROS detoxifications play a major role in restoring embryo metabolic functions after warming[12]. For the first time, our results demonstrated the synergistic effect between both melatonin and cysteamine as antioxidant. This synergistic effect has essential role for improving buffalo embryo development and cryotolerance. These results came partially in accordance with Manjunatha et al.[37] who reported that melatonin supplementation to culture medium of buffalo embryos significantly improved its development. Moreover, Kelly et al.[42] added that the supplementation of cysteamine to the maturation medium improved blastocyst rate of fresh ovine and vitrified bovine oocytes. Also, Oyamada et al.[29] found that cysteamine improved the development of vitrified bovine oocytes. On the opposite side, Mahmoud et al.[43] found no effect for cysteamine on the cryoresistance of oocytes during vitrification in spite of improving the in vitro oocytes maturation.

The current study showed that the perfect dose for buffalo oocytes maturation and culturing was $10 \mathrm{ng} / \mathrm{mL}$ reflecting that melatonin has species/dose dependent effect[31,32]. On conclusion, enriching maturation, culturing and vitrification media of oocytes and embryos with melatonin and/or cysteamine had significantly beneficial effects on buffalo oocyte developmental competence and embryos vitrification procedure outcomes.

\section{Conflict of interest statement}

We declare that we have no conflict of interest.

\section{References}

[1] Edgar DH, Bourne H, Speirs AL, McBain JC. A quantitative analysis of the impact of cryopreservation on the implantation potential of human early cleavage stage embryos. Hum Reprod 2000; 15(1): 175-179.

[2] Leibo SP, Loskutoff NM. Cryobiology of in vitro-derived bovine embryos. Theriogenology 1993; 39: 81-94.

[3] Dattena M, Accardo C, Pilichi S, Isachenko V, Mara L, Chessa B, et al. Comparison of different vitrification protocols on viability after transfer of ovine blastocysts in vitro produced and in vivo derived. Theriogenology 2004; 62(3-4): 481- 493.

[4] Gardiner CS, Salmen JJ, Brandt CJ, Stover SK. Glutathione is present in reproductive tract secretions and improves development of mouse embryos after chemically induced glutathione depletion. Biol Reprod 1998; 59: 431- 436.

[5] Agarwal A, Said TM, Bedaiwy MA, Banerjee J, Alvarez J. Oxidative stress in an assisted reproductive techniques setting. Fertil Steril 2006; 86(3): 503-512.

[6] Ahn HJ, Sohn IP, Kwon HC, Jo DH, Park YD, Min CK. Characteristics of the cell membrane fluidity, actin fibers, and mitochondrial dysfunctions of frozen-thawed two-cell mouse embryos. Mol Reprod Dev 2002; 61: 466476.

[7] Somfai T, Ozawa M, Noguchi J, Kaneko H, KurianiKarja NW, Farhudin $\mathrm{M}$, et al. Developmental competence of in vitro-fertilized porcine oocytes after in vitro maturation and solid surface vitrification: Effect of cryopreservation on oocyte antioxidative system and cell cycle stage. Cryobiology 2007; 55: 115-126.

[8] Rall WF, Fahy GM. Ice-free cryopreservation of mouse embryos at -196 degrees C by vitrification. Nature $1985 ; 313$ : 573-575.

[9] Kuwayama M. Highly efficient vitrification for cryopreservation of human oocytes and embryos: The cryotop method. Theriogenology 2007; 67: $73-80$.

[10]Rios GL, Mucci NC, Kaiser GG, Alberio RH. Effect of container, vitrification volume and warming solution on cryosurvival of in vitroproduced bovine embryos. Anim Reprod Sci 2010; 118: 19-24.

[11]Manjunatha BM, Gupta PSP, Ravindra JP, Devaraj M, Nandi S. In vitro embryo development and blastocyst hatching rates following vitrification of river buffalo embryos produced from oocytes recovered from slaughterhouse ovaries or live animals by ovum pick-up. Anim Reprod. Sci 2008; 104: 419-426.

[12]Donnay I, Auquier P, Kaidi S, Carolan C, Lonergan P, Mermillod P. Vitrification of in vitro produced bovine blastocysts: Methodological studies and developmental capacity. Anim Reprod Sci 1998; 52: 93-104.

[13]Lane M, Maybach JM, Gardner DK. Addition of ascorbate during cryopreservation stimulates subsequent embryo development. Hum Reprod 2002; 17: 2686-2693.

[14]Reiter RJ. Pineal melatonin: Cell biology of its synthesis and of its physiological interactions. Endocr Rev 1991; 12: 151-180. 
[15]Ishizuka B, Kuribayashi Y, Murai K, Amemiya A, Itoh MT. The effect of melatonin on in vitro fertilization and embryo development in mice. $J$ Pineal Res 2000; 28: 48-51.

[16]Okatani Y, Wakatsuki A, Kaneda C. Melatonin increases activities of glutathione peroxidase and superoxide dismutase in fetal rat brain. $J$ Pineal Res 2000; 28: 89-96.

[17]Fischer TW, Kleszczy ski K, Hardkop LH, Kruse N, Zillikens D. Melatonin enhances antioxidative enzyme gene expression (CAT, GPx, SOD), prevents their UVR-induced depletion, and protects against the formation of DNA damage (8-hydroxy-2'-deoxyguanosine) in ex vivo human skin. J Pineal Res 2013; 54: 303-312.

[18]Gao C, Han HB, Tian XZ, Tan DX, Wang L, Zhou GB. Melatonin promotes embryonic development and reduces reactive oxygen species in vitrified mouse 2-cell embryos. J Pineal Res 2012; 52: 305-311.

[19]Reiter RJ, Rosales-Corral SA, Manchester LC, Tan DX. Peripheral reproductive organ health and melatonin: Ready for prime time. Int J Mol Sci 2013; 14: 7231-7232.

[20]León J, Acuña-Castroviejo D, Escames G, Tan DX, Reiter RJ. Melatonin mitigates mitochondrial malfunction. J Pineal Res 2005; 38: 1-9.

[21]Jou MJ, Peng TI, Yu PZ, Jou SB, Reiter RJ, Chen JY. Melatonin protects against common deletion of mitochondrial DNA augmented mitochondrial oxidative stress and apoptosis. J Pineal Res 2007; 43: 389-403.

[22]Leoni G, Berlinguer F, Rosati I, Bogliolo L, Ledda S, Naitana S. Resumption of metabolic activity of vitrified/warmed ovine embryos. Mol Reprod Dev 2003; 64: 207-213.

[23]Succu S, Pasciu V, Manca ME, Chelucci S, Torres-Rovira L, Leoni GG, et al. Dose-dependent effect of melatonin on post-warming development of vitrified ovine embryos. Theriogenology 2014; 81: 1058-1066.

[24]De Matos DG, Furnus CC. The importance of having high glutathione level after bovine in vitro maturation on embryo development: Effect of beta-mercaptoethanol, cysteine and cystine. Theriogenology 2000; 53(3): 761-771.

[25]Lafleur MVM, Hoonveg JJ, Joenje H, Westmijze EJ, Retel J. The ambivalent role of glutathione in the protection of DNA against singlet oxygen. Free Radic Res 1994; 2: 9-17.

[26]Cabiscol E, Tamarit J, Ros J. Oxidative stress in bacteria and protein damage by reactive oxygen species. Int Microbiol 2000; 3(1): 3-8.

[27]Gasparrini B, Neglia G, Palo RD, Campanile G, Zicarelli L. Effect of cysteamine during in vitro maturation on buffalo embryo development. Theriogenology 2000; 54: 1537-1542.

[28]Kobayashi M, Lee ES, Fukui Y. Cysteamine or beta-mercaptoethanol added to a defined maturation medium improves blastocyst formation of porcine oocytes after intra cytoplasmic sperm injection. Theriogenology 2006; 65: 1191-1199.

[29]Oyamada T, Fukui Y. Oxygen tension and medium supplements for in vitro maturation of bovine oocytes cultured individually in a chemically defined medium. J Reprod Dev 2004; 50: 107-117.

[30]Mahmoud KGHM, El-Sokary MMM. Improvement of the efficacy of buffalo oocytes vitrification. Global Veterinaria 2013; 11(4): 420-431.

[31]El-Raey M, Abdel-Ghaffar AE, Sosa GA, Abou El-Roos MEA, Nagai T. Some trials for improving the in-vitro fertilization capacity of bovine oocyte. Ph.D. Thesis. Faculty of Veterinary Medicine, Benha University, Egypt; 2011: 1-247.

[32]El-Raey M, Geshi M, Somfai T, Kaneda M, Hirako M, Abdel-Ghaffar $\mathrm{AE}$, et al. Evidence of melatonin synthesis in the cumulus oocyte complexes and its role in enhancing oocyte maturation in vitro in cattle. Molecular Reprod Dev 2011b; 78(4): 250-262.

[33]Niwa K, Ohgoda O. Synergistic effect of caffeine and heparin on in vitro fertilization of cattle oocytes matured in culture. Theriogenology 1988; 30: 733-741.

[34]Brackett BG, Oliphant G. Capacitation of rabbit spermatozoa in vitro. Biol Reprod 1975; 12: 260-274.

[35]El-Naby Al Al-H H, Mahmoud KGhM, Scholkamy TH, Sosa GAM, Abouel-Roos MEA, Ahmed YF. Influence of epidermal growth factor with cysteamine on in-vitro buffalo embryo development. Egyptian J Vet Sci 2016; 47(1): 27-39.

[36]Mahmoud KGhM, Scholkamy TH, Darwish SF. Improvement of vitrification of in vitro produced buffalo embryos with a special reference to sex ratio following vitrification. Iranian J Veterinary Res 2015; 16(4): 325-330.

[37]Manjunatha BM, Devaraj M, Gupta PSP, Ravindra JP, Nandi S. Effect of taurine and melatonin in the culture medium on buffalo in vitro embryo development. Reprod Domest Anim 2009; 44: 12-16.

[38]Cebrian-Serrano A, Salvador I, Raga E, Dinnyes A, Silvestre M. Beneficial effect of melatonin on blastocyst in vitro production from heat stressed bovine oocytes. Reprod Domest Anim 2013; 48: 738-746.

[39]El-Raey M, Badr MR, Rawash ZM, Darwish GM. Evidences for the role of melatonin as a protective additive during buffalo semen freezing. American J Anim Vet Sci 2014; 9(4): 252-262.

[40]El-Raey M, Badr MR, Assi MM, Rawash ZM. Effect of melatonin on buffalo bull sperm freezability, ultrastructure changes and fertilizing potentials. Assiut Vet Med J 2015; 61(144): 201-208.

[41]He Y, Deng H, Shi M, Bodinga BM, Chen H, Han Z, et al. Melatonin modulates the functions of porcine granulosa cellsvia its membrane receptor MT2 in vitro. Anim Reprod Sci 2016; 172: 164-172.

[42]Kelly J, Kleemann DO, Kuwayama M, Walker S. Effect of cysteamine on survival of bovine and ovine oocytes vitrified using the minimum volume cooling (MVC) cryotop method. Reprod Fertil Dev 2005; 18: 158-158.

[43]Mahmoud KGhM, El-Sokary M, Kandiel MMM, Abou El-Roos MEA, Sosa GMS. Effect of cysteamine during in vitro maturation on viability and meiotic competence of vitrified buffalo oocytes. Iranian J Vet Res 2016; 17(3): 165-170. 